\section{New Trends and Issues Proceedings on Humanities and Social Sciences}

'New Trends and Issues Proceedings on Humanities and Social Sciences

\author{
Volume 4, Issue 2 (2017) 20-30 \\ ISSN 2421-8030 \\ www.prosoc.eu \\ Selected Papers of 1st International Congress on Nursing (ICON-2017) 16 - 18 March 2017 Grand Park Lara Convention \\ Center, Lara - Antalya, Turkey
}

\title{
Determination of attitudes and behaviors towards early diagnosis of cervical cancer of first-degree relatives of women who receive treatment of cervical cancer
}

\begin{abstract}
Nurcan Kirca a *, Department of Nursing, Faculty of Health Sciences, Akdeniz University, 07058, Antalya, Turkey. Asli Sis Celik ${ }^{\text {b }}$, Department of Nursing, Faculty of Health Sciences, Ataturk University, 25000, Erzurum, Turkey. Dilek Kilic ${ }^{c}$, Department of Nursing, Faculty of Health Sciences, Ataturk University, 25000, Erzurum, Turkey.
\end{abstract}

\section{Suggested Citation:}

Kirca, N., Celik, S. A. \& Kilic, D. (2017). Determination of attitudes and behaviors towards early diagnosis of cervical cancer of first-degree relatives of women who receive treatment of cervical cancer.

[Online]. 4(2), pp 20-30. Available from:

www.prosoc.eu

Selection and peer review under responsibility of Prof. Dr. Nesrin Nural,

${ }^{\circ} 2017$ SciencePark Research, Organization \& Counseling. All rights reserved.

, Turkey

\begin{abstract}
This study aims to determine the risk factors, behaviors, participation to screening programs, and attitudes towards early diagnosis of cervical cancer of first-degree relatives of women who receive treatment of cervical cancer.The present study is a descriptive type research. The study was conducted between February and May 2016 in the Oncology and Chemotherapy unit of a university hospital. The study was carried out with 283 first-degree relatives of the patients who receive treatment of cervical cancer in the related unit, and agreed to participate in the study. The "Descriptive Characteristics Form", and the "The Scale of Attitudes towards Early Diagnosis of Cervical Cancer" was used for data collection. 49.1\% of the women was between the ages of $31-40,41.3 \%$ of first marriage age was 18 years old or younger, $52.2 \%$ of first delivery age was 20 years old or younger, $52.2 \%$ and above had 3 or more deliveries. $52.7 \%$ had a genital infection, $45.9 \%$ had vaginal discharge with abundant and malodor, $24.4 \%$ had abnormal vaginal bleeding, and $42 \%$ had bleeding after sexual intercourse. And, $51.6 \%$ was smokers, $32.9 \%$ was taking oral contraceptives for 5 years and above, $98.2 \%$ hadn't had the HPV vaccine and $71.4 \%$ hadn't had a PAP smear test. The mean score of the Scale was $103.27 \pm 10.71$. Women generally have a high level of positive attitudes but the behaviors is insufficient toward early diagnosis of cervical cancer, the majority of women have cervical cancer risk factors and women with risk factors have a low level of positive attitudes toward early diagnosis of cervical cancer.
\end{abstract}

Keywords: Attitudes; behaviors; cervical cancer; early diagnosis; first-degree relatives; Turkey.

* ADDRESS FOR CORRESPONDENCE: Nurcan Kirca, Department of Nursing, Faculty of Health Sciences, Akdeniz University, 07058, Antalya, Turkey. 
Kirca, N., Celik, S. A. \& Kilic, D. (2017). Determination of attitudes and behaviors towards early diagnosis of cervical cancer of first-degree relatives of women who receive treatment of cervical cancer.

[Online]. 4(2), pp 20-30. Available from: www.prosoc.eu

\section{Introduction}

Cervical cancer is the second most common cancer type in women under the age of 45 in the world and it is the third cause of cancer deaths after breast and lung cancer. Cervical cancer is a preventable disease. Screening programs allow its early diagnosis and effective treatment. However, it is still a major cause of death in developing and undeveloped countries. Cervical cancer has a pre-invasive stage and it can be diagnosed and treated at this stage. These are important features of this disease which allow screening and early diagnosis (Public Health Department of Turkey, 2017a; Kanbur \& Capik, 2011; Guner \& Taskiran 2007; Kaya \& Akin 2009; Ozgul, 2007; Taskin, 2016; Tuncer \& Salman, 2004; Tuncer, 2004; Turkish Society of Gynecologic Oncology, 2017; American Cancer Society, 2017a; American Cancer Society, 2017b).

Identification of individuals at risk of cancer and early diagnosis are two important factors in the cancer prevention. All women are at risk of cervical cancer. However, some individual risk factors cause this risk to increase. Many of these risk factors are closely related to adverse health behaviors. The types of risky behaviors identified in the literature are: starting sexual intercourse at an early age ( $<16$ years), having multiple sexual partners, having sex with a person with multiple sexual partners, being at the age of 20 or younger at the time of first pregnancy and delivery, having more than 3 pregnancies or deliveries at the age of 20 or younger, having sexually transmitted disease (especially HPV type 16-18, HSV II and HIV), cigarette use, being between 30 and 55 years of age, using of oral contraceptives over 5 years, overweight, low socioeconomic status, poor hygiene, early menarche, race (Black women), untreated other vaginal infections, abnormal vaginal bleeding, post-sexual bleeding, excessive vaginal discharge, and immunosuppression (Public Health Department of Turkey, 2017a; Kanbur \& Capik, 2011; Guner \& Taskiran 2007; Kaya \& Akin, 2009; Ozgul, 2007; Taskin, 2016; Tuncer \& Salman, 2004; Tuncer, 2004; Turkish Society of Gynecologic Oncology, 2017; American Cancer Society, 2017a; American Cancer Society, 2017b; Ozgul, 2007; Tarwireyi et al., 2003; Pınar et al., 2008; Lim et al., 2016; Wang et al., 2016; Niyazi et al., 2016).

One of the risk factors of cervical cancer is the history of cervical cancer in the mother or sister. The American Cancer Society has reported that women who have a mother or sister with cervical cancer are 2 to 3 times more likely to have cervical cancer 11 . There is a relationship between cervical cancer and genetic transmission. In tumor development, $27 \%$ interaction between underlying factors and genetic structure has been detected. Genetics affects many factors associated with tumor growth. These are as follows; HPV resistance, HPV elimination, disease development time (Magnusson et al., 2000; Weber et al., 2005; Zoodsma et al., 2004).

There is a cervical cancer screening program for women aged 30 to 65 years in Turkey, which has been carried out since 2007 by the KETEM (Cancer Early Diagnosis, Screening and Training Center) affiliated to the Ministry of Health. Women who are registered with the invitation method are asked to refer to family physicians and they are scanned every five years by HPV test or Pap smear test (Public Health Department of Turkey, 2017b). However, participation of women in these screening programs is not sufficient (Reis et al., 2012; Ozmen \& Ozsoy, 2009; Karabulutlu \& Reis, 2011; Egelioglu et al., 2016; Onsuz et al., 2014; Sahin et al., 2014). For this reason, health awareness for early detection of cervical cancer and screening programs should be developed by educating all women, especially women in risk groups. In this study, it is aimed to determine the attitudes of first-degree relatives of women who treated for cervical cancer towards early-diagnosis of cervical cancer, their participation status, and risk factors.

\section{Materials and methods}

This descriptive study was conducted between February and May 2016 at the Oncology and Chemotherapy unit of a University Hospital located at the north eastern part of Turkey. In this study, the aim of the study was explained to cervical cancer patients and they were asked whether they accept their first-degree relative to be included in the study. Finally, cervical cancer patients' first- 
Kirca, N., Celik, S. A. \& Kilic, D. (2017). Determination of attitudes and behaviors towards early diagnosis of cervical cancer of first-degree relatives of women who receive treatment of cervical cancer.

[Online]. 4(2), pp 20-30. Available from: www.prosoc.eu

degree relatives $(n=283)$ (biological mothers or previously or presently sexual active daughters or sisters of these patients) who were literate, who were over 20 years old, who were not diagnosed with cancer, and who did not have hysterectomy surgery were included in this study.

\subsection{Data collection}

Permissions were asked from patients for the participation of their first-degree relatives (mother, daughter, sister). Contact information of their relatives was obtained. The study was explained to firstdegree relatives of patients via phone. Data were collected from the ones who accepted to participate in the study by telephone, e-mail or by interviewing them at the address mentioned. "Descriptive Characteristics Form" and "The Scale of Attitudes towards Early Diagnosis of Cervical Cancer (SAEDCC)" were used in the data collection.

\subsubsection{Descriptive characteristics form}

The survey includes 30 questions about socio-demographic characteristics of women, risk factors of cervical cancer, and prevention, early diagnosis and screening behaviors of women.

\subsubsection{The Scale of Attitudes Towards Early Diagnosis of Cervical Cancer (SAEDCC)}

It was developed by Ozmen and Ozsoy (2009) in order to determine the attitudes of women towards the early detection of cervical cancer. It is composed of 30 items and 4 sub-dimensions. There are 9 items in the "perception of sensitivity" sub-dimension, 8 items in the "perception of seriousness" sub-dimension, 7 items in the "perception of obstacle" sub-dimension, and 6 items in the "perception of benefit" sub-dimension. The items on the scale using the Likert type scaling are evaluated as (1) strictly disagree, (2) disagree, (3) undecided, (4) partially agree, (5) completely agree. Of the 30 items, 22 are positive and 8 are negative. Negative expressions are scored by using reverse-scoring. The highest score that can be taken from the scale is 150 and the lowest score is 30 . The high scores indicate that the attitudes of the individual towards the early diagnosis of cervical cancer are positive. The Cronbach's alpha coefficient for all dimensions and subscales of the scale is between 0.89 and 0.70 (Ozmen \& Ozsoy, 2009). In this study, the Cronbach's alpha coefficient for all dimensions and sub-dimensions is between 0.85 and 0.75 .

\subsection{Ethical principles of the study}

Permission was obtained from the relevant author in order to use the SAEDCC. The required ethics committee approval and written permission from the relevant hospital to collect the data were obtained. Informed consents were also obtained from the women who participated in the study.

\subsection{Evaluation of the data}

The evaluation of the data was done by using the SPSS 20.0 Packet Program and the frequency distribution, Kruskal Wallis and Mann Whitney-U tests were used for the data analysis. KolmogorovSmirnov test was done on all the data and nonparametric tests were used in evaluating the data because it was detected that data were not normally distributed.

\subsection{Study's limitations}

Research results can be generalized to women in the study group.

\section{Results and Discussion}

Of the women, $49.5 \%$ of them were primary school graduates, $94.3 \%$ of them were married, $58.3 \%$ of them were living in the city center, $56.2 \%$ of them were unemployed, $95.4 \%$ of them had low income level, and $78.1 \%$ of them had a health insurance (Table 1).

The difference between the mean scores of Attitudes towards the Early Diagnosis of Cervical Cancer was found to be significant according to the level of education, income status, and health insurance status of women. In addition, it was determined that women who were university graduates, who had 
Kirca, N., Celik, S. A. \& Kilic, D. (2017). Determination of attitudes and behaviors towards early diagnosis of cervical cancer of first-degree relatives of women who receive treatment of cervical cancer.

[Online]. 4(2), pp 20-30. Available from: www.prosoc.eu

the same income level, and who had health insurance showed higher positive attitudes towards early detection of cervical cancer $(p<0.05)$ (Table 1$)$.

Table 1. Socio-demographic characteristics of women and comparison of mean scores of SAEDCC

\begin{tabular}{|c|c|c|c|c|}
\hline $\begin{array}{l}\text { Characteristics } \\
\text { Educational Level }\end{array}$ & $\mathbf{N}$ & $\%$ & Mean $\pm S D$ & Test and $P$ Value \\
\hline Literate & 51 & 18.0 & $100.16 \pm 9.25$ & \\
\hline Primary school & 140 & 49.5 & $100.38 \pm 9.37$ & $\mathrm{KW}=15.020$ \\
\hline High school & 62 & 21.9 & $102.31 \pm 10.32$ & $P<0.05$ \\
\hline University and higher & 30 & 10.6 & $111.23 \pm 10.54$ & \\
\hline \multicolumn{5}{|l|}{ Marital Status } \\
\hline Single & 16 & 5.7 & $102.31 \pm 11.09$ & $U=1923.500$ \\
\hline Married & 267 & 94.3 & $103.32 \pm 10.71$ & $P>0.05$ \\
\hline \multicolumn{5}{|l|}{ Living Place } \\
\hline City center & 165 & 58.3 & $106.80 \pm 11.92$ & \multirow{3}{*}{$\begin{array}{c}K W=0.298 \\
P>0.05\end{array}$} \\
\hline Town center & 42 & 14.8 & $103.61 \pm 11.10$ & \\
\hline Village & 76 & 26.9 & $102.21 \pm 10.05$ & \\
\hline \multicolumn{5}{|l|}{ Employment Status } \\
\hline Employed & 124 & 43.8 & $104.06 \pm 11.13$ & $U=9090.500$ \\
\hline Unemployed & 159 & 56.2 & $102.25 \pm 10.10$ & $P>0.05$ \\
\hline \multicolumn{5}{|l|}{ Income Level } \\
\hline Low income & 270 & 95.4 & $103.02 \pm 10.67$ & $U=1133.000$ \\
\hline Medium income & 13 & 4.6 & $108.38 \pm 10.63$ & $P<0.05$ \\
\hline \multicolumn{5}{|l|}{ Health Insurance } \\
\hline Available & 221 & 78.1 & $109.43 \pm 9.74$ & $U=3357.500$ \\
\hline No & 62 & 21.9 & $101.54 \pm 10.35$ & $P<0.001$ \\
\hline
\end{tabular}

KW= Kruskal Wallis Test, $\mathrm{U}=$ Mann-Whitney U

The American Cancer Society has reported that being overweight is also a risk factor for cervical cancer and that the likelihood of developing cervical adenocarcinoma in overweight women is higher (American Cancer Society 2017b). In this study, it was determined that $27.6 \%$ of the women were obese (Table 2).

Cervical cancer is more often seen between 30 and 55 years of age (Kanbur \& Capik, 2011; Taskin, 2016). It was found that $49.1 \%$ of them were between the ages of 31 and $40,41 \%$ of them were at the age of 41 or older (Table 2 ).

Women who gain the reproductive ability with early menarche get married and start sexual intercourse at an early age. Therefore, they encounter early age pregnancies and excessive fertility problems. These problems increase the cervical cancer risk in the future (Kanbur \& Capik, 2011; Guner \& Taskiran, 2007; Kaya \& Akin, 2009; Turkish Society of Gynecologic Oncology, 2017; American Cancer Society, 2017b, Ozgul, 2007; Pinar et al., 2008; Lim et al., 2016; Wang et al., 2016; Niyazi et al., 2016). Pinar et al. (2008) have found that $53.3 \%$ of the individuals with cervical cancer start their sexual intercourse at the age of 18 or younger. In this study, it was shown that $46.6 \%$ of the women had a menarche age of 12 or younger and thus $41.3 \%$ of them had their first sexual intercourse at the age of 18 or younger. Cervical cancer increases with the number of pregnancies and births. It has been reported that the fact that the number of pregnancies is more than three, and having the first pregnancy and childbirth before the age of 20 are important risk factors for the cervical cancer (Kanbur \& Capik, 2011; Guner \& Taskiran 2007; Kaya \& Akin, 2009; Turkish Society of Gynecologic Oncology, 2017; American Cancer Society, 2017b; Ozgul, 2007; Lim et al., 2016; Wang et al., 2016; Niyazi et al., 2016). In the study of Pinar et al. (2008), it has been shown that the majority of individuals with cervical cancer have the first pregnancy at the age of 18 or younger $(51.1 \%)$ and most of them have more than 3 children at this age (86.7\%). In this study, $60.1 \%$ of women had their first 
Kirca, N., Celik, S. A. \& Kilic, D. (2017). Determination of attitudes and behaviors towards early diagnosis of cervical cancer of first-degree relatives of women who receive treatment of cervical cancer.

[Online]. 4(2), pp 20-30. Available from: www.prosoc.eu

gestational at the age of 20 or younger, $52.5 \%$ had their first childbirth at the age of 20 or younger, and $52.2 \%$ of them had more than three children at this age (Table 2 ).

The abundance of miscarriages and abortions can cause gynecological problems to be experienced intensively. These untreated diseases can lead to malignancy. Pinar et al. (2008) have reported that $66.7 \%$ of cervical cancer women have at least one miscarriage, and $33.3 \%$ of them have at least two abortions. It was detected in this study that $81.7 \%$ of the women had one or more miscarriages, and $66.5 \%$ of them had one or more abortions. Of the women, $45.9 \%$ of them had malodorous vaginal discharge, $24.4 \%$ of them had an abnormal vaginal bleeding, and $42 \%$ of them had a bleeding problem after the sexual intercourse (Table 2).

Unable to apply menstruation and perineum hygiene efficiently and properly may pose a risk in terms of genito-urinary infections. This type of infections, when they are identified at an early period but necessary measures are not taken, serious health problems may appear such asinfertility and cervical cancers (Kanbur \& Capik, 2011; Taskin, 2016). In this study, 52.7\% of women had genital infection (Table 2).

One of the risk factors for cervical cancer is the use of oral contraceptives (OCs). According to the American Cancer Society, prolonged intake of OCs increases the risk of cervical cancer. Human cervical tissue has hormone receptors. Histological changes in the cervical epithelium occur in women using OCs. Immunological changes that increase susceptibility to viral agents develop and the use of OCs causes a mucus secretion that facilitates mutagenesis (American Cancer Society 2017b)

The results of many studies indicate that contraceptives increase the risk of cervical lesions and cancer. It has been shown that there is a positive association between cervical cancer and long-term use of OCs. The risk of cancer increases especially in women who use OCs for 5 years or longer (Moreno et al., 2002; Kjellberg et al., 2000; Moodley et al., 2003). Moreno et al. (2002) have found that HPV DNA-positive women have a 4-fold increase in cervical cancer incidence in case of using oral contraceptives for a long time. In this study, $32.9 \%$ of women were using oral contraceptives for 5 years or more (Table 2 ).

In many studies, it has been shown that cigarette smoking is one of the risk factors of cervical cancer (Ministry of Health, Public Health Department of Turkey, 2017a, Kanbur \& Capik 2011; Guner \& Taskiran, 2007; Turkish Society of Gynecologic Oncology, 2017; American Cancer Society, 2017b; Ozgul, 2007; Tarwireyi et al., 2003; Pinar et al., 2008; Lim et al., 2016; Kjellberg et al., 2000). According to the American Cancer Society (2017b), smoking women are twice more likely to get cervical cancer than non-smokers. Certain chemical substances that are tobacco by-products are found in the cervical mucus of smoking women. Researchers believe that these substances can damage the DNA of cervical cells and contribute to the development of cervical cancer. At the same time, smoking makes the immune system less effective against HPV infections (Kjellberg et al., 2000). In the study of Pınar et al. (2008), 33.3\% of the cases with cervical cancer have reported that they are using more than 10 cigarettes per day. In this study, it was detected that $51.6 \%$ of the women were smoking cigarette (Table 2).

It was shown that the difference between the mean scores of the SAEDCC was significant according to the BMI of women, the number of abortions, active sexual life, and genital infection, malodorous vaginal discharge, abnormal vaginal bleeding, and post-sexual bleeding. Women who had a normal weight, who did not experience abortion, who did not have an active sexual life, and who did not experience any other complaints had more positive attitudes towards the early detection of cervical cancer $(p<0.05)$ (Table 2). 
Kirca, N., Celik, S. A. \& Kilic, D. (2017). Determination of attitudes and behaviors towards early diagnosis of cervical cancer of first-degree relatives of women who receive treatment of cervical cancer.

[Online]. 4(2), pp 20-30. Available from: www.prosoc.eu

Table 2. Women's characteristics associated with risk factors of cervical cancer and comparison of mean scores of SAEDCC

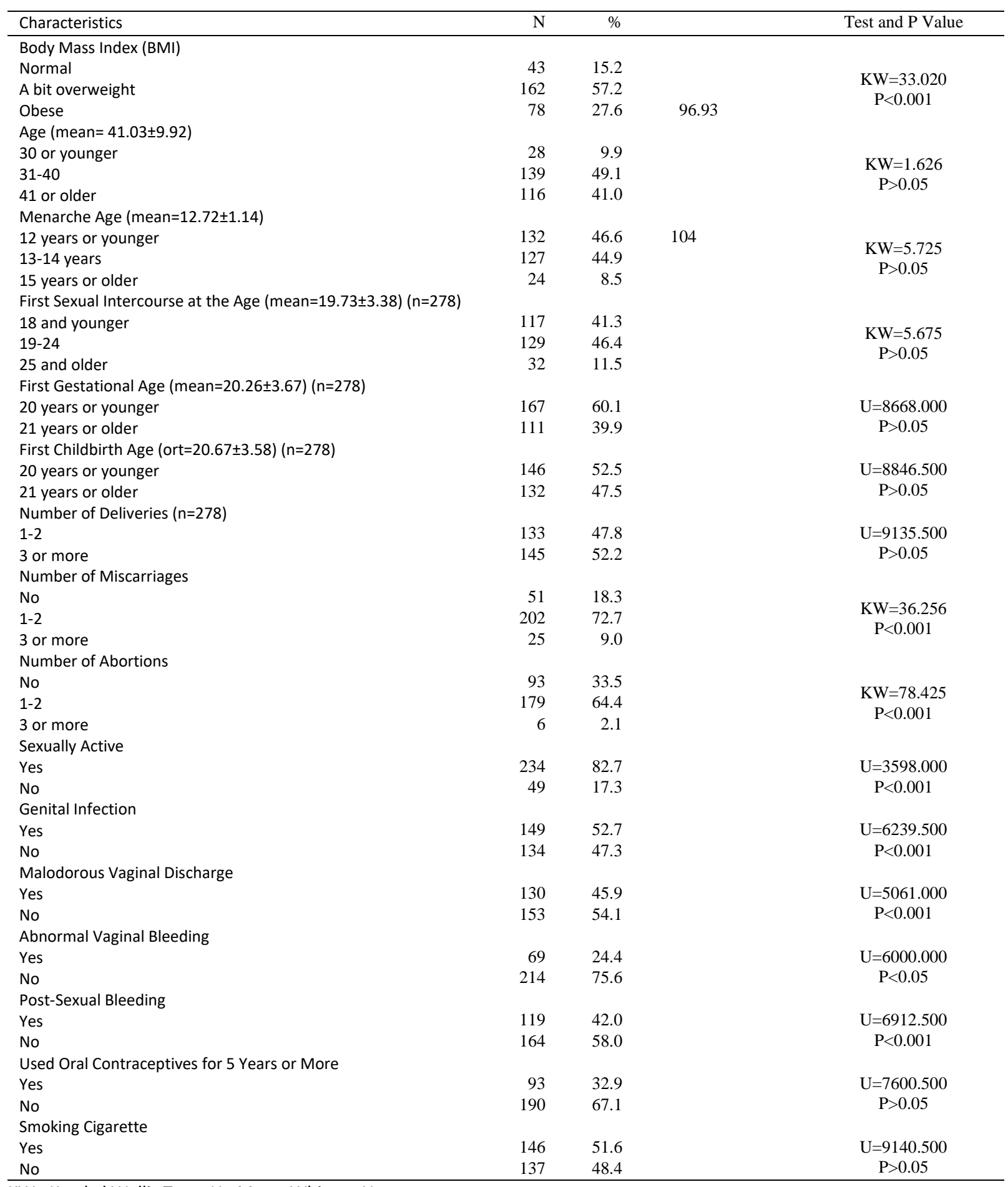

$\mathrm{KW}=$ Kruskal Wallis Test, $\mathrm{U}=$ Mann-Whitney $\mathrm{U}$

In order to prevent cervical cancer, it is primarily necessary to prevent risk factors and to have screenings for early diagnosis (Public Health Department of Turkey, 2017a; Kanbur \& Capik, 2011; Guner \& Taskiran, 2007; Kaya \& Akin, 2009; Ozgul, 2007; Taskin, 2016; Tuncer \& Salman, 2004; Tuncer, 
Kirca, N., Celik, S. A. \& Kilic, D. (2017). Determination of attitudes and behaviors towards early diagnosis of cervical cancer of first-degree relatives of women who receive treatment of cervical cancer.

[Online]. 4(2), pp 20-30. Available from: www.prosoc.eu

2004; Turkish Society of Gynecologic Oncology, 2017; American Cancer Society, 2017a; American Cancer Society, 2017b). In order to be protected from the risk factors and to have cancer screening, it is necessary to be knowledgeable about this issue. Studies have shown that a significant proportion of women do not know the risk factors of cervical cancer and the importance of the Pap smear test. The fact that women do not know the risk factors and smear test may lead to inadequate use of methods related to the prevention, early diagnosis, and treatment (Ozgul, 2007; Wang et al., 2016; Magnusson et al., 2000; Ministry of Health, Public Health Department of Turkey, 2017b). Of the women, $59.7 \%$ of them stated that they did not have knowledge about cervical cancer, $78.4 \%$ of them stated that they did not know the aim of the Pap smear test, and $58.7 \%$ of them stated that they did not know about the Pap smear test and thus they did not have the test (Table 3). Our findings show that knowledge levels of women are not sufficient to protect themselves against cervical cancer despite the presence of cervical cancer cases in their families. These results are similar to the findings of other studies (Reis et al., 2012; Karabulutlu \& Reis, 2011; Egelioglu et al., 2016; Onsuz et al., 2014; Sahin et al., 2014).

It has been recently emphasized that HPV is the most important cause of cervical cancer development. It is thought that HPV types 16 and 18 are responsible for the $70 \%$ of cervical cancers all over the world (Pinar et al., 2008; Wang et al., 2016; Niyazi et al., 2016; Magnusson et al., 2000; Weber et al., 2005; Zoodsma et al., 2004). The Centers for Disease Control and Prevention (CDC) (2017) has shown that the current HPV vaccine which can prevent cervical cancer can also prevent the majority (about 28,000 ) of gynecological cancers. The quadrivalent and bivalent vaccines received a vaccination license in Turkey in respectively 2007 and 2008, but they have not yet entered the routine vaccination schedule. In this study, $79.5 \%$ of women reported that they had not heard of HPV vaccination before, and $98.2 \%$ of them did not have HPV vaccination before (Table 3 ). The percentages of women who do not know about HPV vaccination and who do not have HPV vaccination are similar to the results of studies conducted in Turkey on the subject (Reis et al., 2012; Karabulutlu \& Reis, 2011; Egelioglu et al., 2016; Onsuz et al., 2014; Sahin et al., 2014).

If other factors causing cervical cancer are taken into account, cervical cancer screenings or Pap smear testing should be done regularly, even if HPV vaccination has been administered. There are many health behaviors that reduce the risk of cervical cancer, but no behavior is as effective as routine Pap smear test. The Pap smear test detects cervical cancer with up to 90-95\% accuracy before symptoms occur. It has been reported that regular application of Pap smear screening programs can significantly reduce morbidity and mortality due to cervical cancer in the community (Somer, 2008; Centers for Disease Control and Prevention, 2017). However, $71.4 \%$ of women in this study stated that they did not have a Pap smear test. In this study, $73.1 \%$ of them women stated that they did not have health complaint, $58.7 \%$ of them stated that they did not know about the test, $22.6 \%$ of them stated that they were afraid of being diagnosed with cancer (Table 3 ). Therefore, these women did not have the Pap smear test. The percentage of women who do not have Pap smear is similar to the results of studies conducted in Turkey on the subject (Reis et al., 2012; Karabulutlu \& Reis, 2011; Egelioglu et al., 2016; Onsuz et al., 2014; Sahin et al., 2014). These results show that the practice of Pap smear test in Turkey is very low.

Pinar et al. (2008) have found that $80 \%$ of individuals with cervical cancer do not visit the doctor for regular gynecological controls. Cervical cancer can be diagnosed early by regular gynecological examinations. In order to achieve this, regular gynecologic examinations must be performed before the cervical cancer is diagnosed and treatment of existing genital infections should be done. Turkish women do not believe that the gynecological examination is necessary when they do not have health complaints. Studies have shown that these beliefs of Turkish women affect having gynecological examination and Pap smear test (Reis et al., 2012; Karabulutlu \& Reis, 2011; Egelioglu et al., 2016; Onsuz et al., 2014; Sahin et al., 2014). It was also found in this study that $91.9 \%$ of women did not have regular health check in case of any problem and similarly $98.9 \%$ of them did not have regular gynecological examination. Furthermore, respectively $99.6 \%, 69.6 \%, 50.9 \%$, and $49.8 \%$ of them did not go for a gynecological examination because of the absence of health complaint, and negligence, fear, and shame (Table 3). 
Kirca, N., Celik, S. A. \& Kilic, D. (2017). Determination of attitudes and behaviors towards early diagnosis of cervical cancer of first-degree relatives of women who receive treatment of cervical cancer.

[Online]. 4(2), pp 20-30. Available from: www.prosoc.eu

Sexual activity is also one of the risk factors for cervical cancer. In the literature, it is recommended to have an annual Pap smear test for all women who are 18 years of age and sexually active (Ministry of Health, Public Health Department of Turkey, 2017a; Kanbur \& Capik, 2011; Kaya \& Akin, 2009; Ozgul, 2007; Turkish Society of Gynecologic Oncology, 2017; American Cancer Society, 2017a; Ministry of Health, Public Health Department of Turkey, 2017b). In this study, although $82.7 \%$ of the women were sexually active (Table 2), 71.4\% of them stated that they did not have any Pap smear test before (Table 3).The difference between the mean scores of SAEDCC was found to be significant according to the status of having knowledge about cervical cancer, the status of having regular health check in case of a health problem, and the status of having a Pap smear test. In addition, attitudes towards early diagnosis of cervical cancer were found to be more positive in women who had information about cervical cancer, had regular health checkups, and had a Pap smear test before $(p<0.05)$ (Table 3).

Table 3. Women's characteristics associated with prevention, early diagnosis and screening of cervical cancer and comparison of mean scores of SAEDCC

\begin{tabular}{|c|c|c|c|c|c|}
\hline Characteristics & $\mathrm{N}$ & $\%$ & Mean \pm SD & Test and $\mathrm{P}$ Value & \\
\hline \multicolumn{6}{|l|}{ Have Knowledge About Cervical Cancer } \\
\hline Yes & 114 & 40.3 & $105.57 \pm 10.62$ & \multicolumn{2}{|l|}{$U=6452.000$} \\
\hline No & 169 & 59.7 & $99.85 \pm 9.94$ & \multicolumn{2}{|l|}{$P<0.001$} \\
\hline \multicolumn{6}{|l|}{ Heard of HPV Vaccination } \\
\hline Yes & 58 & 20.5 & $105.81 \pm 11.66$ & \multicolumn{2}{|l|}{$U=5693.000$} \\
\hline No & 225 & 79.5 & $102.61 \pm 10.38$ & \multicolumn{2}{|l|}{$P>0.05$} \\
\hline \multicolumn{6}{|l|}{ Have HPV Vaccination } \\
\hline Yes & 5 & 1.8 & $109.40 \pm 10.62$ & \multicolumn{2}{|l|}{$U=493.500$} \\
\hline No & 278 & 98.2 & $103.16 \pm 10.70$ & \multicolumn{2}{|l|}{$P>0.05$} \\
\hline \multicolumn{6}{|l|}{ Exercise Regularly } \\
\hline Yes & 22 & 7.8 & $109.95 \pm 8.73$ & \multicolumn{2}{|l|}{$U=1800.500$} \\
\hline No & 261 & 92.2 & $102.70 \pm 10.69$ & \multicolumn{2}{|l|}{$\mathrm{P}<0.05$} \\
\hline \multicolumn{6}{|c|}{ Regularly Visit The Doctor for Health Checks When There was any Problem } \\
\hline Yes & 23 & 8.1 & $109.73 \pm 8.59$ & \multicolumn{2}{|l|}{$U=1861.500$} \\
\hline No & 260 & 91.9 & $102.70 \pm 10.71$ & \multicolumn{2}{|l|}{$P<0.05$} \\
\hline \multicolumn{6}{|l|}{ Have a Regular Gynecological Examination } \\
\hline Yes & 3 & 1.1 & $104.66 \pm 4.93$ & \multicolumn{2}{|l|}{$U=343.000$} \\
\hline No & 280 & 98.9 & $103.25 \pm 10.76$ & \multicolumn{2}{|l|}{$P>0.05$} \\
\hline \multicolumn{6}{|c|}{ Reasons for not going to a Regular Gynecological Examination* } \\
\hline No complaints & 280 & 99.6 & & & $* *$ \\
\hline Neglect & 197 & 69.6 & & & \\
\hline Shame & 141 & 49.8 & & & \\
\hline Fear & 144 & 50.9 & & & \\
\hline Feeling pain & 31 & 11.0 & & & \\
\hline High rate & 74 & 26.1 & & & \\
\hline No health insurance & 50 & 17.7 & & & \\
\hline \multicolumn{6}{|l|}{ Know The Aim of The Pap Smear Test } \\
\hline Yes & 61 & 21.6 & $103.46 \pm 10.54$ & \multicolumn{2}{|l|}{$U=6139.500$} \\
\hline No & 222 & 78.4 & $102.55 \pm 11.39$ & \multicolumn{2}{|l|}{$P>0.05$} \\
\hline \multicolumn{6}{|l|}{ Have Pap Smear Test } \\
\hline Never & 202 & 71.4 & $102.43 \pm 10.46$ & \multicolumn{2}{|l|}{$U=6764.000$} \\
\hline Once & 81 & 28.7 & $105.50 \pm 11.11$ & $\mathrm{P}<0.05$ & \\
\hline Reasons for not having Pap Smear Test* & & & & & \\
\hline No complaints & 202 & 73.1 & & & $* *$ \\
\hline Neglect & 98 & 34.6 & & & \\
\hline Did not know about the test & 166 & 58.7 & & & \\
\hline Shame & 62 & 21.9 & & & \\
\hline Not having time & 78 & 27.6 & & & \\
\hline Do not know how to go where the test is done & 62 & 21.9 & & & \\
\hline High rate & 52 & 18.4 & & & \\
\hline No health insurance & 43 & 15.2 & & & \\
\hline Fear & 64 & 22.6 & & & \\
\hline
\end{tabular}

$\mathrm{U}=$ Mann-Whitney $\mathrm{U},{ }^{*}$ More than one answer, ${ }^{* *}$ No comparison

When the average score of the SAEDCC was examined, it was determined that women generally had a high level of positive attitude toward early diagnosis of cervical cancer. When the subscale 
Kirca, N., Celik, S. A. \& Kilic, D. (2017). Determination of attitudes and behaviors towards early diagnosis of cervical cancer of first-degree relatives of women who receive treatment of cervical cancer.

[Online]. 4(2), pp 20-30. Available from: www.prosoc.eu

scores of the scale were examined, it was found that the degree of "perception of seriousness" and "perception of benefit" was moderately positive but the degree of "perception of sensitivity" and "perception of disability" was lowly positive (Table 4).

The health belief model states that there is a relationship between individual's attitudes with the development of his/her health behavior, adoption and practice of these behaviors. This model also suggests that people show protective health behaviors when a disease or condition threatens themselves. It is suggested that there are four main concepts that are effective on preventive health behaviors. The "Perception of susceptibility" is the belief that one is susceptible to the disease. The "Perception of seriousness" is that one believes that the illness is serious and is concerned. The "Perception of benefit" is to feel that protective behaviors are useful in protecting from the disease. The "Perception of obstacles" are negative aspects such as embarrassment and pain perceived in the formation of anticipatory protective behavior (Baltas, 2000; Champion, 1984; Cam \& Gumus, 2006).

From this point of view, it can be stated that most of the women are not aware of the seriousness of the cervical cancer, they do not believe that the health protection behaviors for cancer prevention and early diagnosis have cancer-protective effects, they do not think that they can also have cervical cancer one day, and they do not apply health behaviors sufficiently. This idea is supported by the statements of women who specify that the reasons for not going to regular gynecological examinations, to have low rates of HPV vaccination and Pap smear testing are often caused by neglect and being ashamed (Table 3). 
Kirca, N., Celik, S. A. \& Kilic, D. (2017). Determination of attitudes and behaviors towards early diagnosis of cervical cancer of first-degree relatives of women who receive treatment of cervical cancer.

[Online]. 4(2), pp 20-30. Available from: www.prosoc.eu

Cam, O. \& Gumus, A. B. (2006). Psychosocial factors influencing early detection behaviors in breast and cervical cancer.

(1), 81-93.

Centers for Disease Control and Prevention, Human Papillomavirus (HPV) (2017). Retrieved from https://www.cdc.gov/hpv/parents/vaccine.html on 27 January 2017.

Champion, V. L. (1984). Instrument development for health belief model constructs. 73-85.

Egelioglu, C. N., Top, E. D. \& Isik, G. (2016). Cervical cancer and pap smear test health beliefs and health promoting lifestyle of women in Turkey.

Guner, H. \& Taskiran, C. (2007). Cervical cancer epidemiology and human papilloma virus.

(1), 11-19.

Kanbur, A. \& Capik, C. (2011). Cervical cancer prevention, early diagnosis-screening methods and midwives/ nurses role.

(1), 61-72.

Karabulutlu, O. \& Reis, N. (2011). The investigation of life styles adopted by women living in Erzurum as regards cervical cancer risk.

Kaya, M. \& Akin, A. (2009).

(6), 1625-1635

Kjellberg, L., Hallmans, G., Åhren, A. M., Johansson, R., Bergman, F., Wadell, G. \& Dillner, J. (2000). Smoking, diet, pregnancy and oral contraceptive use as risk factors for cervical intra-epithelial neoplasia in relation to human papillomavirus infection.

(7), 1332-1338.

Lim, S., Lee, S. H., Lee, K. B. \& Park, C. Y. (2016). The influence of number of high risk factors on clinical outcomes in patients with early-stage cervical cancer after radical hysterectomy and adjuvant chemoradiation. (3), 184-191.

Magnusson, P. K., Lichtenstein, P. \& Gyllensten, U. B. (2000). Heritability of cervical tumours. (5), 698-701.

Ministry of Health, Public Health Department of Turkey, Cancer Department. (2017). National standards for cervical cancer screening. Retrieved from http://kanser.gov.tr/Dosya/tarama/serviks.pdf on 26 January 2017.

Ministry of Health, Public Health Department of Turkey, Cancer Department. (2017). Cervical cancer. Retrieved from http://kanser.gov.tr/kanser/kanser-turleri/56-serviks-kanseri.html on 26 January 2017.

Moodley, M., Moodley, J., Chetty, R. \& Herrington, C. S. (2003). The role of steroid contraceptive hormones in the pathogenesis of invasive cervical cancer: a review. 103-110.

Moreno, V., Bosch, F. X., Munoz, N., Meijer, C. J., Shah, K. V., Walboomers, J. M., Herrero, R. \& Franceschi, S. (2002). Effect of oral contraceptives on risk of cervical cancer in women with human papillomavirus infection: The IARC Multicentric Case-Control Study.

(9312), 1085-1092

Niyazi, M., Husaiyin, S., Han, L., Mamat, H., Husaiyin, K. \& Wang, L. (2016). Prevalence of and risk factors for high-risk human papillomavirus infection: A population-based study from Hetian, Xinjiang, China.

(1), 46-51.

Onsuz, MF., Hidiroglu, S., Sarioz, A., Metintas, S. \& Karavus, M. (2014). Knowledge, attitudes and behaviors of women over 20 years old on cervix cancer in Istanbul, Turkey.

(20), 8801-8807.

Ozgul, N. (2007). Cervical cancer status and cervical cancer screening studies in Turkey. In: Tuncer A. M, (Ed). (pp.349-358). Ankara: Onur Publishing.

Ozmen, D. \& Ozsoy, S. (2009). Developing a valid and reliable instrument to examine attitudes toward early diagnosis of cervical cancer by using health belief model approach.

(1), 51-69.

Pinar, G., Algier, L., Dogan, N. \& Kaya, N. (2008). Determination of the risk factors in individuals with gynecological cancer.

(4), 208-216.

Reis, N., Bebis, H., Kose, S., Sis, A., Engin, R. \& Yavan, T. (2012). Knowledge, behavior and beliefs related to cervical cancer and screening among Turkish Women. 1463-1470.

Sahin, M. K., Sahin, G., Dikici, M. F., Igde, F. A. \& Yaris, F. (2014). Women's perceptions and attitudes about cervical cancer in Turkey: Kato's device as an alternative to the Pap smear. 905-910.

Somer, A. (2008). Human papillomavirus (HPV) vaccines. (2), 50-55.

Tarwireyi, F., Chirenje, Z. M. \& Rusakaniko, R. (2003). Cancer of the Cervix: Knowledge, beliefs and screening behaviours of health workers in Mudzi District in Mashonaland East Province, Zimbabwe.

$(7-8), 83-86$.

Taskin, L. (2016).

. Ankara: Academician Medical Bookstore.

Tuncer, S. \& Salman, M. C. (2004). Cervical intraepithelial neoplasia. In: Gunalp, S. \& Tuncer, S. (Eds),

Tuncer, Z. S. (2004).

In: Gunalp, S. \& Tuncer, S. (Eds), (pp.653-668). Ankara: Pelikan Publishing.

(pp.669-682). Ankara: Pelikan Publishing. 
Kirca, N., Celik, S. A. \& Kilic, D. (2017). Determination of attitudes and behaviors towards early diagnosis of cervical cancer of first-degree relatives of women who receive treatment of cervical cancer.

[Online]. 4(2), pp 20-30. Available from: www.prosoc.eu

Turkish Society of Gynecologic Oncology, Cervical Cancer (2017). Retrieved from http://www.trsgo.org/menu/152/rahim-agzi-serviks-kanseri on 26 January 2017.

Wang, J, Andrae, B., Sundstrom, K., Strom, P., Plone, A., Elfstrom, KM., Arnheim-Dahlstrom, L., Dillner, J. \& Sparén, P. (2016). Risk of invasive cervical cancer after atypical glandular cells in cervical screening: nationwide cohort study. 352-276.

Weber, W., De-Sabata, M. S., Paredes, R. M., Rodriguez, G., Santos, C., Sabillon, J. U. \& Zwahlen, M. (2005). Cancer in first degree relatives of Latin American women with cervical cancer. A pilot study. (2B), 1219-1223.

Zoodsma, M., Sijmons, R. H., de Vries, E. G. \& van der Zee, A. G. (2004). Familial cervical cancer: Case reports, review and clinical implications.

(2), 99-105. 